\title{
Management of walled-off necrosis with nasocystic irrigation with hydrogen peroxide versus biflanged metal stent: randomized controlled trial*
}

\section{(ㄷ)(i) $\Theta$}

Authors

Sudhir Maharshi ${ }^{1}$, Shyam Sunder Sharma ${ }^{1}$, Sandeep Ratra ${ }^{1}$, Bharat Sapra, Dhruv Sharma²

Institutions

1 Department of Gastroenterology, SMS Medical College and Hospitals, Jaipur, India

2 Ananta Institute of Medical Sciences and Research Center, Rajsamand, India

submitted 29.8.2020

accepted after revision 10.3.2021

\section{Bibliography}

Endosc Int Open 2021; 09: E1108-E1115

DOI 10.1055/a-1480-7115

ISSN 2364-3722

(C) 2021. The Author(s).

This is an open access article published by Thieme under the terms of the Creative Commons Attribution-NonDerivative-NonCommercial License, permitting copying and reproduction so long as the original work is given appropriate credit. Contents may not be used for commercial purposes, or adapted, remixed, transformed or built upon. (https://creativecommons.org/licenses/by-nc-nd/4.0/)

Georg Thieme Verlag KG, Rüdigerstraße 14,

70469 Stuttgart, Germany

\section{Corresponding author}

Shyam Sunder SharmaSenior Professor, , Department of Gastroenterology, Room No. 303, SMS Hospital, Jaipur,

Rajasthan 302004, India

Fax: +91-141-2564222

shyamsharma4@rediffmail.com

\section{ABSTRACT}

Background and study aims Walled-off necrosis (WON) is a known complication of acute necrotizing pancreatitis (ANP). There is no study comparing nasocystic irrigation with hydrogen peroxide $\left(\mathrm{H}_{2} \mathrm{O}_{2}\right)$ versus biflanged metal stent (BMS) in the management of WON. The aim of this study was to compare the clinical efficacy of both the treatment strategies.

Patients and methods This study was conducted on patients with symptomatic WON who were randomized to nasocystic irrigation with $\mathrm{H}_{2} \mathrm{O}_{2}$ (Group A) and BMS placement (Group B). Primary outcomes were clinical and technical success while secondary outcomes were procedure time, adverse events, need for additional procedures, duration of hospitalization, and mortality.

Results Fifty patients were randomized into two groups. Group $A(n=25$, age $37.8 \pm 17.6$ years, 16 men) and Group $B(n=25$, age $41.8 \pm 15.2$ years, 17 men). There were no significant differences in baseline characteristics between the two groups. The most common etiology of pancreatitis was alcohol, observed in 27 (54\%) patients. Technical success ( $100 \%$ vs $96 \%, P=0.98$ ), clinical success ( $84 \%$ vs $76 \%, P=$ 0.76 ), requirement of additional procedures ( $16 \%$ vs $24 \%$, $P=0.70$ ) and adverse events ( 4 vs $7, P=0.06$ ) were comparable in both the groups. The duration to clinical success (34.4 \pm 12 vs $14.8 \pm 10.8$ days, $P=0.001$ ) and procedure time ( $36 \pm 15$ vs $18 \pm 12$ minutes, $P=0.01$ ) were longer in Group A compared to Group B.

Conclusions Nasocystic irrigation with $\mathrm{H}_{2} \mathrm{O}_{2}$ and BMS are equally effective in the management of WON but time to clinical success and procedure time is longer with nasocystic irrigation.

\footnotetext{
* This Manuscript was accepted for lecture presentation in the Digestive Disease Week 2020, Chicago (Abstract-3348028, Presenting Number 730) and presented virtually as DDW 2020 got cancelled in view of Covid 19 Pandemic
}

\section{Introduction}

Pancreatic fluid collections are classified according to revised Atlanta classification into acute peri-pancreatic fluid collections or acute necrotic collections within 4 weeks after onset and pseudocyst or walled-off necrosis (WON) after 4 weeks [ 1 , 2]. WON is a mature, encapsulated collection of pancreatic 
and/or peri-pancreatic necrosis that has developed a well-defined inflammatory wall. It is a difficult-to-treat collection but symptomatic WON always needs treatment. WON has been treated with surgical necrosectomy in the past, but management has changed over time towards endoscopic procedures and laparoscopic and radiological interventions [3].

Endoscopic drainage procedures such as placement of multiple plastic stents, use of a nasocystic catheter along with aggressive irrigation, use of fully covered self-expanding biflanged metallic stents (BMS)/lumen apposing metal stents (LAMS), and direct debridement of solid necrotic material by endoscopic necrosectomy has led to significant improvement in the results of endotherapy [4-8]. Two different endoscopic ultrasound (EUS)-guided step-up approaches for management of WON using LAMS and plastic stents have been described recently $[8,9]$. Few studies revealed that irrigation with hydrogen peroxide $\left(\mathrm{H}_{2} \mathrm{O}_{2}\right)$ is effective in the management of WON. Hydrogen peroxide decomposes into water and oxygen when combined with organic tissue and therefore facilitates removal of necrotic debris. It also causes irritation in the wall of WON, leading to formation of granulation tissue and fibrosis, causing obliteration of the cavity [9-15]. To date, there is no study on comparison of nasocystic irrigation with $\mathrm{H}_{2} \mathrm{O}_{2}$ versus BMS/ LAMS placement in the management of WON, thus we planned this study with the aim of comparing the clinical efficacy of both techniques.

\section{Patients and methods}

This randomized controlled trial (CTRI/2019/05/019185) was conducted at SMS Hospital, Jaipur, India, a tertiary care center, between May 2019 and April 2020. Informed consent in writing was obtained from each patient and the study protocol conformed to the ethical guidelines of the 2013 declaration of Helsinki as reflected in a priori approval by the appropriate institutional review committee. All the procedures were done by two expert endosonologists (S.S.S. and S.M.), both experienced in therapeutic endoscopic ultrasound (EUS) and who have individually placed $>100$ plastic stents/nasocystic drain and > 40 BMS/ LAMS for WON drainage. Patients of with acute necrotizing pancreatitis (ANP), aged 18 to 85 years who had symptomatic WON located adjacent to the stomach or duodenum were included in the study. The indications for drainage included infected WON, persistent pain abdomen, symptomatic gastrointestinal/biliary obstruction, and failure to thrive. Exclusion criteria were patients with WON located $>1.5 \mathrm{~cm}$ from the gastrointestinal lumen, patients with coagulopathy (international normalized ratio $>1.5$ or platelet count $<50000 / \mu \mathrm{L})$, pregnancy, and patients with an indwelling percutaneous drainage catheter. Enrolled study patients were randomized using computer-generated randomization tables by a statistician not involved directly in patient care. The sequences were concealed until a decision to enroll a patient was made after assessment for eligibility and receiving informed consent. The patients were divided to receive the following interventions: Group A - EUS-guided transmural placement of plastic stent and nasocystic drain for $\mathrm{H}_{2} \mathrm{O}_{2}$ irrigation and Group B - EUS-guided BMS placement. Pa- tients in Group A underwent EUS-guided transmural placement of one plastic stent and one nasocystic drain in to cystic cavity.

Nasocystic irrigation was done with $3 \% \mathrm{H}_{2} \mathrm{O}_{2}, 20 \mathrm{~mL} . \mathrm{H}_{2} \mathrm{O}_{2}$ was diluted with $80 \mathrm{~mL}$ distilled water and this mixture was gently pushed into the WON cavity followed by clamping of nasocystic tube for 1 hour. This procedure was repeated every 6 hours until clinical success was achieved or a maximum for 7 days. The nasocystic drain was removed after 7 days. Patients in Group B underwent EUS-guided BMS placement. Patients in both the groups received intravenous (IV) antibiotics (thirdgeneration cephalosporin or according to blood/cystic fluid culture and sensitivity) along with other supportive treatment. Direct endoscopic necrosectomy (DEN) was considered in both groups as when required with forward-viewing gastroscope (GIF XTQ-160, Olympus, Tokyo, Japan) when patients were not improving with the treatment. WON was defined as per the Atlanta classification as an organized collection with both liquid and necrotic solid components on imaging (contrast-enhanced computed tomography [CECT], magnetic resonance imaging [MRI], and/or EUS) developing 4 weeks after ANP [1]. On imaging the details of WON including location, size, number, wall thickness, interposing collaterals, percentage of solid debris, and proximity to the upper gastrointestinal tract were noted. Technical success was defined as successful deployment of a plastic stent with nasocystic drain in Group A and BMS in Group B. Clinical success was defined as improvement in symptoms and resolution of WON to $<2 \mathrm{~cm}$ without a need for a second procedure. Procedure time was measured as the time from passage of the echo-endoscope into the gastrointestinal lumen to perform transmural drainage until the end of the endoscopic procedure. Duration of hospitalization was defined as the time to hospital discharge from the day of the index endoscopic intervention. Post-procedure adverse events (AEs) were noted. Bleeding was defined as any bleeding during the procedure or post-procedure that required hemostasis, blood product transfusion, or inpatient observation.

Presence of infection in WON was suspected based on patient clinical course, high leucocyte counts, and presence of gas in WON on imaging. Infection was further confirmed by gram smear and culture of aspirated fluid. A complete clinical assessment including the demographics and details of pancreatitis were recorded. Laboratory parameters including complete blood count, liver function test, renal function test, prothrombin time, lipid profile, random blood sugar, serum amylase, lipase, and serum calcium were done. Blood and cystic fluid culture and sensitivity was done as when required. Primary outcomes were clinical and technical success of both the procedures. Secondary outcomes were procedure time, AEs, need for additional procedures, duration of hospitalization, and mortality.

\section{Procedure details}

All EUS-guided drainage procedures were performed in an inpatient setting. All the procedures were performed with the patient in the left lateral position under conscious sedation with intravenous midazolam and pentazocine. A therapeutic linear echo-endoscope (UCT-180; Olympus, Tokyo, Japan) was used. 
After detail assessment the WON was punctured with a 19gauge fine-needle aspiration needle from the stomach or duodenum. Five milliliters of fluid was aspirated and sent for gram smear and culture. A 0.035-inch guidewire (Jag Wire; Boston Scientific, United States) was then inserted through the needle into the WON cavity and coiled (at least 2-3 loops) under EUS guidance and we did not use fluoroscopy during the procedures as we were doing these procedures regularly without fluoroscopy. Tract dilation was performed with a 6F cystotome (Endoflex GmbH Dusseldorf, Germany).

Subsequently, a 6-mm balloon dilator (Hurricane; Boston Scientific, United States) was used to further dilate the tract. Another guidewire was placed into the cyst cavity with the help of cannula. A $7 \mathrm{Fr} \times 10 \mathrm{~cm}$ double pigtail plastic stent was inserted first over the wire with distal end into the cyst cavity and proximal end in stomach or duodenum. This was followed by a $7 \mathrm{Fr}$ nasocystic drain placement over the second guide wire under EUS guidance. In Group B, placement of a second guidewire was not needed and after dilation with the balloon, the BMS (Ottomed Endoscopy, Mitra, India) was deployed under EUS guidance. This BMS is a dedicated self-expandable, fully covered bi-flanged metal stent for the drainage of pancreatic fluid collections. The stent is short in length $(30 \mathrm{~mm})$ with diameter of $14.5 \mathrm{~mm}$ and flare diameter of $34 \mathrm{~mm}$ and is available only in India. A $7 \mathrm{Fr} \times 10 \mathrm{~cm}$ double pigtail stent was also placed through BMS. After the drainage procedure, patients were observed in the hospital for symptomatic improvement or development of any AEs. Oral liquids were allowed 6 hours after the procedure. IV antibiotics were continued for 3 days which was later changed to oral for the next 7 days. Transabdominal ultrasound imaging was performed on day 3 to document reduction in size of the collection and before discharge from hospital. If required the antibiotics were changed according to microbial culture and sensitivity pattern. Patients were asked to follow up after 15 days, at 1 month and then every month until 3 months. Abdominal ultrasound was done after the completion of the third week to confirm the resolution of WON and the BMS was removed while the plastic stent was removed after 6 months.

\section{Statistical analysis}

The sample size was calculated based on a previously published study done by Bang JY et al, which showed a difference in treatment success between plastic and metallic SEMS of 3.1\% [16]. The calculated sample size was 25 patients in each arm, to detect a $5 \%$ difference in success rate between the two groups with $5 \%$ type 1 error, $80 \%$ power for a two-tailed log-rank test, and $10 \%$ drop out rate. The statistical analysis was performed using statistical package for social sciences (SPSS) trial version 23.0 for windows (SPSS, Chicago Illinois, United States). Categorical variables were expressed as absolute number with percentage while continuous data were presented as means \pm standard deviations (SDs). The significance of differences between treatment groups was assessed using a student $t$-test, chi-square or Fisher's exact tests as appropriate. $P<0.05$ was considered significant.

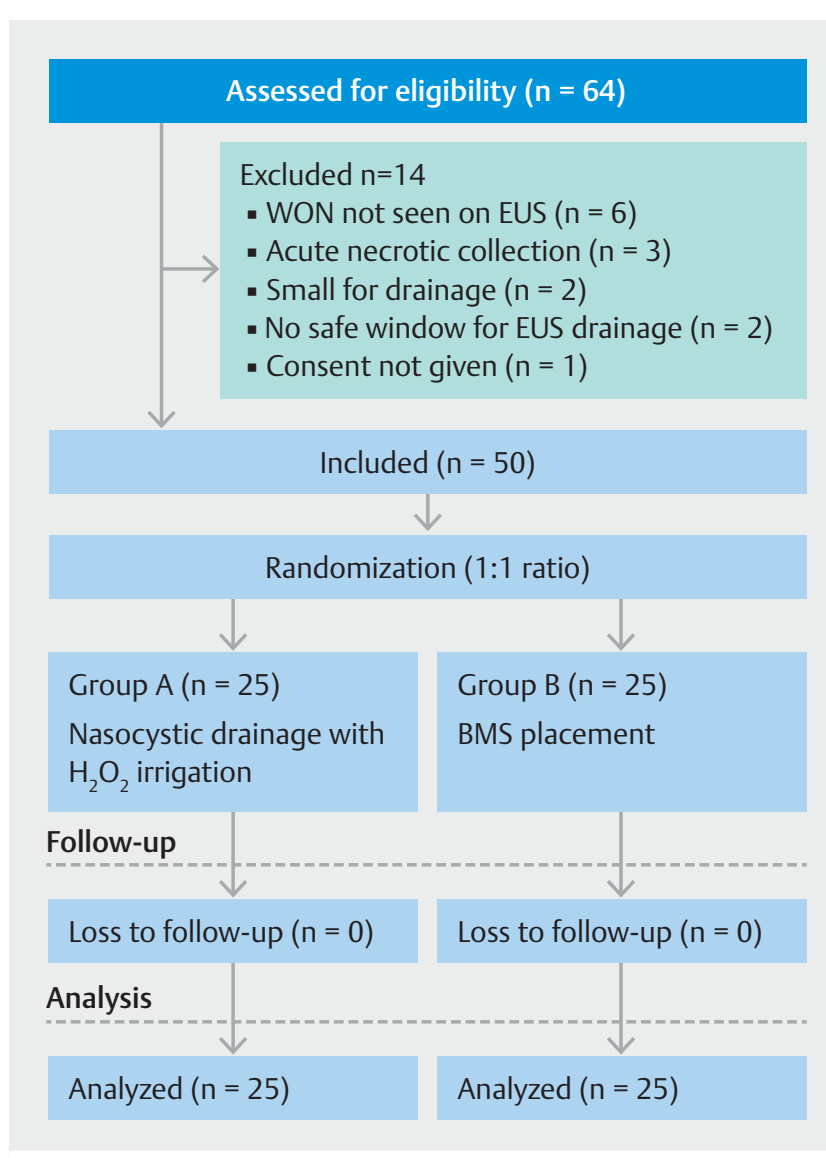

- Fig. 1 Flowchart of study design. WON, walled-off necrosis; EUS, endoscopic ultrasound; $\mathrm{H}_{2} \mathrm{O}_{2}$, hydrogen peroxide; BMS, biflanged metal stent.

\section{Results}

A total of 64 patients of symptomatic WON who were scheduled for EUS-guided management were assessed during the study period. Based on exclusion criteria, 14 patients were excluded. Fifty patients who met the inclusion criteria were randomized in 1:1 ratio. The flowchart of the study design is shown in > Fig. 1. There were 33 males (66.6\%) and 17 females $(33.4 \%)$ with mean age of $38.9 \pm 16.8$ years in the study population. There was no significant differences in baseline characteristics including demography, etiology of pancreatitis, presenting symptoms, location, size of WON, amount of debris, and laboratory parameters between the two groups as shown in - Table 1 and - Table 2. A total of 50 patients were randomized during study period, 25 patients to each group. All the patients were symptomatic for more than 2 months (7335 days, range 30-210 days). Most common etiology of pancreatitis was alcoholic, among these nine patients (18\%) had changes of chronic pancreatitis on imaging. Patients with chronic pancreatitis were also comparable ( $16 \%$ vs $20 \% ; P=0.15)$ in both the groups. Thirty-five patients (70\%) presented with evidence of infection in WON and these patients were also comparable ( $72 \%$ vs $68 \% ; P=0.9$ ) in both the groups. The mean size of WON was $10.3 \pm 4.1 \times 8.8 \pm 3.1 \mathrm{~cm}$ with $32 \pm 10.4 \%(25-60 \%)$ solid 
- Table 1 Baseline characteristics of the study patients.

\begin{tabular}{|c|c|c|c|c|}
\hline & Total study patients $(n=50)$ & Group A $(n=25)$ & Group B $(n=25)$ & $P$ value $^{1}$ \\
\hline Age $($ mean $\pm S D)$ & $38.9 \pm 16.8$ & $37.8 \pm 17.6$ & $41.8 \pm 15.2$ & 0.18 \\
\hline Male patients - n (\%) & $33(66.6 \%)$ & $16(64.0 \%)$ & $17(68.0 \%)$ & 0.30 \\
\hline \multicolumn{5}{|l|}{ Etiology of pancreatitis - n(\%) } \\
\hline " Alcohol & $27(54 \%)$ & $12(48 \%)$ & $15(60 \%)$ & 0.56 \\
\hline - Trauma & $4(8 \%)$ & $4(16 \%)$ & - & - \\
\hline - Biliary & $9(18 \%)$ & $4(16.0 \%)$ & $5(20.0 \%)$ & 0.76 \\
\hline - Idiopathic & $10(20 \%)$ & $5(20.0 \%)$ & $5(20 \%)$ & 0.54 \\
\hline \multicolumn{5}{|l|}{ Symptoms - n(\%) } \\
\hline - Pain abdomen & $50(100 \%)$ & $25(100 \%)$ & $25(100 \%)$ & 1 \\
\hline - Fever & $33(66.6 \%)$ & $17(68 \%)$ & $16(64 \%)$ & 0.98 \\
\hline - Vomiting/early satiety & $27(54 \%)$ & $13(52 \%)$ & $14(56 \%)$ & 0.86 \\
\hline Duration of symptoms in days (mean \pm SD) & $73 \pm 35$ & $69 \pm 38$ & $79 \pm 42$ & 0.46 \\
\hline \multicolumn{5}{|l|}{ Size of WON in cm (mean \pm SD) } \\
\hline Transverse axis & $10.3 \pm 4.1$ & $11.1 \pm 4.0$ & $9.8 \pm 4.2$ & 0.98 \\
\hline Anteroposterior axis & $8.8 \pm 3.1$ & $9.4 \pm 3.2$ & $7.9 \pm 3.4$ & 0.88 \\
\hline Amount of debris (mean \pm SD) \% & $32 \pm 10.4$ & $32 \pm 11.6$ & $33 \pm 12.5$ & 0.99 \\
\hline \multicolumn{5}{|l|}{ WON location - n (\%) } \\
\hline Head/uncinate & $21(42 \%)$ & $12(48 \%)$ & $9(36 \%)$ & 0.76 \\
\hline Body/tail & $29(58 \%)$ & $15(60 \%)$ & $14(56 \%)$ & 0.89 \\
\hline WON infection & $35(70 \%)$ & $18(72 \%)$ & $17(68 \%)$ & 0.90 \\
\hline \multicolumn{5}{|l|}{ Route of drainage - $\mathrm{n}(\%)$} \\
\hline Transgastric & $47(94 \%)$ & $23(92 \%)$ & $24(96 \%)$ & 0.99 \\
\hline Transduodenal & $3(6 \%)$ & $2(8 \%)$ & $1(4 \%)$ & 0.76 \\
\hline Underlying chronic pancreatitis - n (\%) & $9(18 \%)$ & $4(16 \%)$ & $5(20) \%$ & 0.15 \\
\hline
\end{tabular}

component. The solid component was $<50 \%$ in the majority 47 ( $94 \%$ ) of our study patients while it was $>50 \%$ in only three patients ( 1 in Group A and 2 in Group B). The majority (58\%) of WONs were located in the body and tail region of pancreas and the route of drainage was transgastric in 47 patients (94\%). Study patients had low hemoglobin $(10.4 \pm 4.1)$ and low albu$\min (3.0 \pm 0.72)$ levels; both laboratory parameters were comparable in the study groups.

\section{Outcome measures}

The primary outcome measures of technical success (100\% vs $96 \% ; P=0.98)$ and clinical success ( $84 \%$ vs $76 \% ; P=0.76)$ were comparable in both the groups, as shown in $>$ Table 3 . Procedure time ( $36 \pm 15$ vs $18 \pm 12$ minutes; $P=0.01)$ and time to achieve clinical success ( $34.4 \pm 12$ vs $14.8 \pm 10.8$ days; $P=0.001$ ) were longer in Group A compared to Group B. Other outcome measures like duration of hospitalization, requirement of addi- tional procedures, requirement of readmissions, need of transpapillary pancreatic duct stenting, and AEs were comparable in both groups as shown in > Table 3. In Group A, successful deployment of the plastic stent and nasocystic drain was achieved in all 25 patients, while in Group B, one patient had technical failure in successful deployment of BMS. This patient had an internally migrated BMS due to obscured endoscopic view during deployment due to a rapid gush of dirty fluid from WON. This case was managed by placing a plastic stent through the BMS in the WON immediately and on the second day, the tract was re-dilated and the same LAMS was retrieved and repositioned successfully.

Twenty-one patients (84\%) in Group A achieved clinical success without the need for additional procedures, while four patients (16\%) required an additional procedure. Of these four patients, two required DEN and two required percutaneous drainage due to persistent abdominal pain, new onset fever 
- Table 2 Laboratory parameters for the study population.

\begin{tabular}{|l|c|c|c|c|}
\hline Parameters & Total study patients (n=50) & Group A (n=25) & Group B (n=25) \\
\hline Hemoglobin (gm\%) & $10.4 \pm 4.1$ & $10.1 \pm 4.4$ & $10.93 \pm 3.14$ \\
\hline Total leucocyte count $\left(\times 10^{9}\right.$ cells/L) & $12.2 \pm 3.5$ & $12.3 \pm 3.3$ & $11.9 \pm 3.6$ \\
\hline RBS (mg/dL) & 120.7 & $126 \pm 46$ & $115.6 \pm 75$ \\
\hline Serum bilirubin (mg/dL) & $1.6 \pm 0.86$ & $1.8 \pm 1.02$ & $1.4 \pm 0.64$ \\
\hline Serum albumin (gm/dL) & $3.0 \pm 0.72$ & $3.1 \pm 0.68$ & $3.0 \pm 0.67$ \\
\hline SGOT (IU/L) & $64 \pm 15$ & $69.7 \pm 14$ & $58 \pm 18$ \\
\hline SGPT (IU/L) & $45.6 \pm 16$ & $46.3 \pm 18$ & $40.3 \pm 17$ \\
\hline ALP (IU/L) & $140 \pm 29$ & $144 \pm 24$ & $135 \pm 35$ \\
\hline Serum amylase (IU/L) & $280 \pm 86$ & $271 \pm 90$ & 0.98 \\
\hline Serum lipase (IU/L) & $196 \pm 80$ & $183 \pm 84$ & 0.19 \\
\hline RBS, random blood sugar; SGOT, aspartate aminotransferase; SGPT, alanine aminotransferase; ALP, alkaline phosphatase. & $294 \pm 85$ \\
\hline
\end{tabular}

- Table 3 Outcome measures in both study groups.

\begin{tabular}{|c|c|c|c|}
\hline & Group A $(n=25)$ & Group B $(n=25)$ & $P$ value \\
\hline Technical success $-n(\%)$ & $25(100 \%)$ & $24(96 \%)$ & 0.98 \\
\hline Clinical success - $\mathrm{n}(\%)$ & $21(84 \%)$ & $19(76 \%)$ & 0.76 \\
\hline Procedure time in minutes (mean $\pm S D$ ) & $36 \pm 15$ & $18 \pm 12$ & 0.01 \\
\hline Duration to get clinical success in days (mean \pm SD) & $34.4 \pm 12$ & $14.8 \pm 10.8$ & 0.001 \\
\hline Trans-papillary PD stenting - n (\%) & $2(8 \%)$ & $3(12 \%)$ & 0.64 \\
\hline Additional procedures required - $\mathrm{n}(\%)$ & $4(16 \%)$ & $6(24 \%)$ & 0.70 \\
\hline Duration of hospitalization in days (mean \pm SD) & $7 \pm 2.8$ & $5 \pm 2.4$ & 0.15 \\
\hline Requirement of readmission $-\mathrm{n}(\%)$ & $8(32 \%)$ & $6(24 \%)$ & 0.19 \\
\hline \multicolumn{4}{|l|}{ Adverse events $-\mathrm{n}(\%)$} \\
\hline - Clinical & $4(16 \%)$ & $4(16 \%)$ & 1.0 \\
\hline - Stent migration & 0 & $3(12 \%)$ & 0.06 \\
\hline Uneventful removal of stent $-\mathrm{n}(\%)$ & $25(100 \%)$ & $23(92 \%)$ & 0.5 \\
\hline WON recurrence $-\mathrm{n}(\%)$ & $1(4 \%)$ & 0 & 0.98 \\
\hline
\end{tabular}

and leucocytosis. In these two patients who required percutaneous drainage, DEN was attempted but it was not successful. In Group B 19(76\%) achieved clinical success while remaining six patients required additional procedure. Of these six patients, four required DEN while the other two were managed by placement of plastic stent and nasocystic drainage with $\mathrm{H}_{2} \mathrm{O}_{2}$ irrigation in view of persistent symptoms. The procedure for successful BMS deployment is shown in > Fig. 2. Two patients in Group A and three in Group B required transpapillary pancreatic duct stenting in view of pancreatic duct leakage and dilated pancreatic duct with persistent pain abdomen in patients of chronic pancreatitis. Pancreatic duct leak was confirmed in symptomatic patients on imaging (MRI or abdominal
CECT). Pancreatic stenting was done 1 month after the index procedure in patients who had persistent symptoms and documented pancreatic duct leak.

The clinical AEs of post-procedure WON infection manifested as persistent pain abdomen and new-onset fever associated with leucocytosis was present in four patients (16\%) in Group A and two patients (8\%) in Group B. In Group B one patient had gastric mucosal bleeding during the procedure, which was managed endoscopically by local adrenalin (1:10000) injection and application of cautery (argon plasma coagulation) and one patient developed perforation required surgical management. In Group B, 3 patients had stent-related AEs. The first patient had internal migrated stent during the deployment, which was 

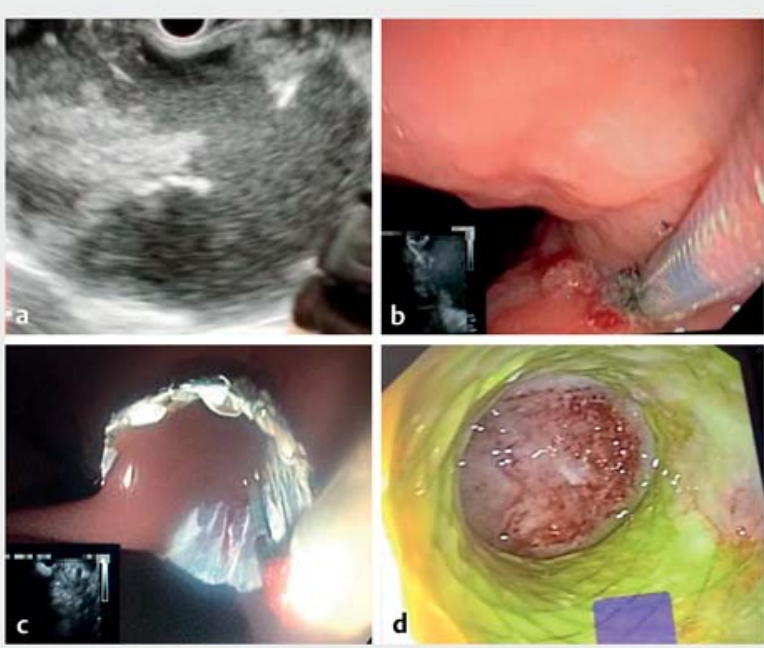

Fig. 2 Endoscopic ultrasound (EUS)-guided drainage of walledoff necrosis (WON) using biflanged metal stent (BMS). a EUS image of WON. b Endoscopic image showing insertion of BMS in the WON cavity. c Successful deployment of BMS draining dirty fluid in gastric lumen. $\mathbf{d}$ Endoscopic view of WON cavity through BMS after 3 weeks showing collapsed cavity with healthy granulation tissue.

repositioned on the next day as discussed earlier. The second patient also had an internally migrated stent when he came for stent removal after 3 weeks. The tract was redilated and the stent was retrieved with rat tooth forceps using a forward-viewing endoscope; this patient developed a pneumoperitoneum after stent removal and required surgical management. The third patient also developed internal migration of stent and was lost to follow-up initially and later presented after 3 months requiring laparoscopic removal of LAMS. None of the patients developed an embolic event in Group A due to $\mathrm{H}_{2} \mathrm{O}_{2}$ irrigation. At the end of 3-month follow-up, one patient in Group A developed recurrence of WON, while in Group B, none of the patients developed recurrence. No mortality was documented during the study period in any group.

\section{Discussion}

Today, WON is managed by EUS using plastic or covered metal stents. In this single-center study on 50 patients with WON, we compared two different management approaches: $\mathrm{H}_{2} \mathrm{O}_{2}$ nasocystic irrigation and BMS. Our study revealed that technical success $(100 \%$ vs $96 \%, P=0.98)$, clinical success $(84 \%$ vs $76 \%, P=$ 0.76 ), requirement for additional procedures ( $16 \%$ vs $24 \%, P=$ 0.70 ), and AEs (4 vs $7, P=0.06$ ) were comparable in both groups. The time to clinical success $(34.4 \pm 12$ vs $14.8 \pm 10.8$ days, $P=0.001)$ and procedure time ( $36 \pm 15$ vs $18 \pm 12$ minutes, $P=0.01$ ) were longer in Group A compared to Group B.

Biflanged metal stents/LAMS for the management of WON have the advantage of quick and easy deployment with a high success rate, making the whole procedure of EUS-guided drainage more efficient and safer $[9,17,18]$. There is no study in the literature comparing the efficacy of $\mathrm{H}_{2} \mathrm{O}_{2}$ nasocystic irrigation and BMS in the management of WON. For the first time, we compared the efficacy of both the techniques and found that both are equally effective. The efficacy of $\mathrm{H}_{2} \mathrm{O}_{2}$ irrigation in the management of WON has been proven in previously published studies [9-15]. In a study on 19 patients, the clinical efficacy of $\mathrm{H}_{2} \mathrm{O}_{2}$ irrigation was $94.7 \%$ with $15.7 \%$ AEs [12]. Other studies have shown that there is significant improvement in success rates with $\mathrm{H}_{2} \mathrm{O}_{2}$ nasocystic irrigation in patients who were not responding after BMS/LAMS placement $[9,11,12]$. Another study revealed transluminal retroperitoneal endoscopic necroscectomy with use of $\mathrm{H}_{2} \mathrm{O}_{2}$ was effective in $90 \%$ of patients and concluded that $\mathrm{H}_{2} \mathrm{O}_{2}$ irrigation results in a reduction in the number of endoscopic sessions and timing [10]. A case series on 14 patients showed that $\mathrm{H}_{2} \mathrm{O}_{2}$ irrigation helps with necrotic tissue dislodgment, debridement, and debris extraction during endotherapy [14]. This likely is the reason for the slightly less reinterventions and more clinical success (although not statistically significant) in Group A compared to Group B in our study. To date, multiple studies have proven the efficacy of metal stents in EUS-guided drainage of WON [14,16,19-21]. In our results, similar efficacy between two groups is likely due to use of $\mathrm{H}_{2} \mathrm{O}_{2}$, which causes liquefaction of necrotic material resulting in chemical necrosectomy and also controls local sepsis. It is likely that these actions of $\mathrm{H}_{2} \mathrm{O}_{2}$ resulted in excellent outcomes in Group A. The additional advantages of using BMS/LAMS include a wider lumen with adequate spontaneous drainage, decreased chance of recurrent stent occlusion, and ability to perform DEN $[16,22]$. The drawback with BMS/LAMS is that they cannot be left in situ for a long period. The reported technical success of metal stents ranges from $91 \%$ to $100 \%$ and for nasocystic drain, from $70 \%$ to $95 \%[9,11-15,23]$. In our study the technical success rate for nasocystic drain placement was $100 \%$ and for BMS was $96 \%$, similar to previously published studies. AEs in pancreatic fluid collection drainage using metal stent placements ranged from $5 \%$ to $21 \%[16,21,24,25]$. A study reported three times higher rates of AEs with plastic stents compared with metal stents [21]. In our study, the AEs were comparable in both groups and similar results have been reported in previously published studies $[14,16,19]$. The need for an additional procedure with metal stents reported in previous studies ranged from $4 \%$ to $79 \%$ [24-27]. This heterogeneity was due to inclusion of both the pseudocyst and WON patients. In our study, the need for additional procedures ( $16 \%$ vs $24 \%, P=0.70$ ) was also comparable in both groups. We used nasocystic $\mathrm{H}_{2} \mathrm{O}_{2}$ irrigation in two patients in Group $\mathrm{B}$ who did not achieve clinical success and even DEN was not successful in these patients as a step-up management approach $[8,9]$. The large amount of solid component in a few study patients may be the cause for failure of therapy and requirement for additional procedures. The migration rate for metal stents in various studies ranges from $0 \%$ to $11 \%[24,25]$. In our study we observed internal migration in three patients $(12 \%)$, results similar to previously published studies $[9,24,25]$. None of our study patients developed an embolic event with $\mathrm{H}_{2} \mathrm{O}_{2}$ irrigation, although it was reported in a few studies [28-32]. Embolic events are more likely if $\mathrm{H}_{2} \mathrm{O}_{2}$ irrigation is done with high pres- 
sure. In our study, patients underwent slow, continuous $\mathrm{H}_{2} \mathrm{O}_{2}$ irrigation after placement of a nasocystic drainage catheter.

The strengths of our study are first, we proved the efficacy of nasocystic irrigation with $\mathrm{H}_{2} \mathrm{O}_{2}$ is equivalent to BMS in the treatment of WON in a randomized controlled trial for the first time in the literature. Second, we excluded patients with pseudocyst and provided comprehensive data on the different clinical and procedure-related outcomes. There are a few limitations in our study. First, we evaluated only a single design of BMS, so the study results cannot be generalized to other designs of BMS/ LAMS. Second, this is a single-center study and the procedures were done by expert endosonologists, which may raise the concern about the universality of the study results. Third, we did not assess the cost analysis of the two treatment techniques. Fourth, the duration of follow-up was short, so the recurrence rate may not be accurate. Larger prospective multicenter studies are required to further validate and generalize the results.

\section{Conclusions}

In conclusion, BMS and nasocystic irrigation with $\mathrm{H}_{2} \mathrm{O}_{2}$ are equally effective in the treatment of WON but time to clinical success and procedure time was longer in the nasocystic irrigation group. AEs were comparable in the groups.

\section{Acknowledgement}

The authors thanks Himanshu Sapra- (Ann \& Robert H. Lurie Children's Hospital of Chicago) for statistical assistance and Jaya Maharshi for typing, formatting, and technical assistance.

\section{Competing interests}

The authors declare that they have no conflict of interest.

\section{References}

[1] Banks PA, Bollen TL, Dervenis C et al. Classification of acute pancreatitis-2012: revision of the Atlanta classification and definitions by international consensus. Gut 2013; 62: 102-111

[2] Rana SS, Bhasin DK, Reddy YR et al. Morphological features of fluid collections on endoscopic ultrasound in acute necrotizing pancreatitis: Do they change overtime? Ann Gastroenterol 2014; 27: 258-261

[3] Sharma V, Rana SS, Bhasin DK. Endoscopic ultrasound guided interventional procedures. World J Gastrointest Endosc 2015; 7: 628-642

[4] Varadarajulu S, Rana SS, Bhasin DK. Endoscopic therapy for pancreatic duct leaks and disruptions. Gastrointest Endosc Clin N Am 2013; 23 : 863-892

[5] Bang JY, Hawes R, Bartolucci A et al. Efficacy of metal and plastic stents for transmural drainage of pancreatic fluid collections: A systematic review. Dig Endosc 2015; 27: 486-498

[6] Varadarajulu S, Phadnis MA, Christein JD et al. Multiple transluminal gateway technique for EUSguided drainage of symptomatic walledoff pancreatic necrosis. Gastrointest Endosc 2011; 74: 74-80

[7] Gardner TB, Chahal P, Papachristou Gl et al. A comparison of direct endoscopic necrosectomy with transmural endoscopic drainage for the treatment of walled-off pancreatic necrosis. Gastrointest Endosc 2009; 69: 1085-1094

[8] Rana SS, Sharma V, Sharma R et al. Endoscopic ultrasound guided transmural drainage of walled off pancreatic necrosis using a "stepup" approach: A single centre experience. Pancreatology 2017; 17: 203-208

[9] Lakhtakia S, Basha J, Talukdar R et al. Endoscopic "step-up approach" using a dedicated bi-flanged metal stent reduces the need for direct necrosectomy in walled-off necrosis (with videos). Gastrointest Endosc 2017; 85: 1243-1252

[10] Abdelhafez M, Elnegouly M, Hasab Allah MS. Transluminal retroperitoneal endoscopic necrosectomy with the use of hydrogen peroxide and without external irrigation: a novel approach for the treatment of walled-off pancreatic necrosis. Surg Endosc 2013; 27: 3911-3920

[11] Bansal RK, Puri R, Choudhray NS et al. Endoscopic pancreatic necrosectomy: why scuff when you can flush the muck-make it an easy row to hoe. Endosc Int Open 2017; 5: E847-E853

[12] Parra V, Kedia P, Zerbo $S$ et al. Drainage of infected pancreatic necrosis by using 2 lumen-apposing metal stents, a nasocystic drain, and hydrogen peroxide. Gastrointest Endosc 2015; 81: 1261

[13] Othman MO, Elhanafi S, Saadi M et al. Extended cystogastrostomy with hydrogen peroxide irrigation facilitates endoscopic pancreatic necrosectomy. Diagn Ther Endosc 2017; 2017: 1-5

[14] Siddiqui AA, Easler J, Strongin A et al. Hydrogen peroxide-assisted endoscopic necrosectomy for walled-off pancreatic necrosis: a dual center pilot experience. Dig Dis Sci 2014; 59: 687-690

[15] Chen Yl, Yang J, Friedland S et al. Lumen apposing metal stents are superior to plastic stents in pancreatic walled-off necrosis: a large international multicentre study. Endosc Int Open 2019; 07: E347-E354

[16] Bang JY, Navaneethan U, Hasan MK et al. Non-superiority of lumenapposing metal stents over plastic stents for drainage of walled-off necrosis in a randomised trial. Gut 2019; 68: 1200-1209

[17] Itoi T, Binmoeller KF, Shah J et al. Clinical evaluation of a novel lumenapposing metal stent for endosonography-guided pancreatic pseudocyst and gallbladder drainage (with videos). Gastrointest Endosc 2012; 75: 870-876

[18] Mukai S, Itoi T, Sofuni A et al. Clinical evaluation of endoscopic ultrasonography- guided drainage using a novel flared-type biflanged metal stent for pancreatic fluid collection. Endosc Ultrasound 2015; 4: $120-125$

[19] Lee BU, Song T], Lee SS et al. Newly designed, fully covered metal stents for endoscopic ultrasound (EUS)-guided transmural drainage of peri-pancreatic fluid collections: a prospective randomized study. Endoscopy 2014; 46: 1078-1084

[20] Siddiqui AA, Kowaiski TE, Loren DE et al. Fully covered self-expanding metal stents versus lumen-apposing fully covered self-expanding metal stent versus plastic stents for endoscopic drainage of pancreatic walled-off necrosis: clinical outcomes and success. Gastrointest Endosc 2017; 85: 758-765

[21] Mukai S, Itoi T, Baron TH et al. Endoscopic ultrasound-guided placement of plastic vs. biflanged metal stents for therapy of walled-off necrosis: a retrospective single centre series. Endoscopy 2015; 47: 47-55

[22] Bang JY, Hawes R, Bartolucci A et al. Efficacy of metal and plastic stents for transmural drainage of pancreatic fluid collections: a systematic review. Dig Endosc 2015; 27: 486-498

[23] Giovannini M, Pesenti C, Rolland AL et al. Endoscopic ultrasoundguided drainage of pancreatic pseudocysts or pancreatic abscesses using a therapeutic echo endoscope. Endoscopy 2001; 33: 473-477

[24] Chandran S, Efthymiou M, Kaffes A et al. Management of pancreatic collections with a novel endoscopically placed fully covered self-expandable metal stent: a national experience (with videos). Gastrointest Endosc 2015; 81: 127-135 
[25] Walter D, Will U, Sanchez-Yague A et al. A novel lumen-apposing metal stent for endoscopic ultrasound-guided drainage of pancreatic fluid collections: a prospective cohort study. Endoscopy 2015; 47: 63-67

[26] Sharaiha RZ, DeFilippis EM, Kedia P et al. Metal versus plastic for pancreatic pseudocyst drainage: clinical outcomes and success. Gastrointest Endosc 2015; 82: 822-827

[27] Yamamoto N, Isayama H, Kawakami $\mathrm{H}$ et al. Preliminary report on a new, fully covered, metal stent designed for the treatment of pancreatic fluid collections. Gastrointest Endosc 2013; 77: 809-814

[28] Beattie C, Harry LE, Hamilton SA et al. Cardiac arrest following hydrogen peroxide irrigation of a breast wound. J Plast Reconstr Aesthetic Surg 2010; 63: 253-254
[29] Huang C, Pik J. Tension pneumocephalus and oxygen emboli from hydrogen peroxide irrigation. J Clin Neurosci 2014; 21: 323-325

[30] Benali ZEA, Abdedaim H, Omari D. Massive gas embolism secondary in the use of intraoperative hydrogen peroxide: still use to lavage with this liquid? Pan Afr Med J 2013; 16: 124

[31] Patankar PS, Joshi SS, Choudhari KA. Air-embolism and cerebral ischaemia following epidural hydrogen peroxide irrigation in a closed lumbar cavity. Br J Neurosurg 2014; 28: 556-558

[32] Zhang J, Zhang C, Yan J. Massive cerebral gas embolism under discectomy due to hydrogen peroxide irrigation. Case Rep Neurol Med 2015; 2015: 1-4 